\title{
Association of ankylosing spondylitis with radiographically and clinically diagnosed apical periodontitis: A cross-sectional study
}

\section{Związek zesztywniającego zapalenia stawów kręgosłupa z zapaleniem tkanek okołowierzchołkowych rozpoznawanym radiologicznie i klinicznie - badanie przekrojowe}

\author{
Ertuğrul Karataş ${ }^{1, A-D, F}$, Ayhan Ku2 ${ }^{2, A, B}$, Ebru Tepecik ${ }^{1, B}$ \\ ${ }^{1}$ Department of Endodontics, Faculty of Dentistry, Atatürk University, Erzurum, Turkey \\ ${ }^{2}$ Department of Physical Medicine and Rehabilitation, Faculty of Medicine, Atatürk University, Erzurum, Turkey \\ A - research concept and design; $\mathrm{B}$ - collection and/or assembly of data; $\mathrm{C}$ - data analysis and interpretation; \\ $D$ - writing the article; $E$ - critical revision of the article; $F$ - final approval of the article
}

\section{Address for correspondence \\ Ertuğrul Karataş}

E-mail: dtertu@windowslive.com

Funding sources

None declared

Conflict of interest

None declared

Received on July 3, 2019

Reviewed on August 27, 2019

Accepted on November 21, 2019

Published online on February 27, 2020

Cite as

Karataş E, Kul A, Tepecik E. Association of ankylosing spondylitis with radiographically and clinically diagnosed apical periodontitis: A cross-sectional study. Dent Med Probl. 2020;57(2):171-175. doi:10.17219/dmp/114463

DOI

10.17219/dmp/114463

Copyright

C 2020 by Wroclaw Medical University

This is an article distributed under the terms of the

Creative Commons Attribution 3.0 Unported License (CC BY 3.0)

(https://creativecommons.org/licenses/by/3.0/).

\section{Abstract}

Background. There are no studies evaluating the possible association between ankylosing spondylitis (AS) and apical periodontitis (AP).

Objectives. The aim of the present cross-sectional study was to investigate the possible association between AS and AP.

Material and methods. Fifty patients diagnosed with AS, receiving treatment at the Rheumatology Clinic in Erzurum, Turkey, were included in the experimental group. Another 50 age- and gender-matched individuals without any history of systemic disease were included in the study as the control group. All patients were examined radiographically and clinically to diagnose the presence of AP. The following data was recorded for all patients: the smoking habit, the number of teeth present, the number of teeth with AP, the number of root canal-treated (RCT) teeth, and the number of RCT teeth with AP.

Results. There were 1,283 teeth in the AS group and 1,305 in the control group. There was a significant association between teeth with $\mathrm{AP}$ and $\mathrm{AS}$, as the prevalence of teeth with $\mathrm{AP}$ was significantly lower in the control group (1.3\%) than in the AS group (2.9\%) (OR (odds ratio) $=2.250 ; p=0.005)$. There was no statistically significant difference between the groups in terms of the number of RCT teeth and RCT teeth with $\operatorname{AP}(p>0.05)$.

Conclusions. Ankylosing spondylitis is significantly associated with an increased prevalence of AP. It can be concluded that patients with AS can be more prone to develop AP. However, AS does not reduce the success rate of endodontic treatment, because there was no significant difference between the AS and control groups in terms of RCT teeth with AP.

Key words: ankylosing spondylitis, apical periodontitis, endodontics

Słowa kluczowe: zesztywniające zapalenie stawów kręgosłupa, zapalenie tkanek okołowierzchołkowych, endodoncja 


\section{Introduction}

Ankylosing spondylitis (AS) is a chronic inflammatory autoimmune condition with a prevalence of $0.1-1.4 \%$ in the general population. ${ }^{1}$ It generally affects patients under the age of 40 and has a higher incidence in males. ${ }^{2}$ Ankylosing spondylitis is characterized by enthesitis, spondylitis and sacroilitis, ${ }^{3}$ and the underlying mechanism triggering the inflammatory process is believed to be autoimmune or autoinflammatory in nature. Increased levels of interleukin 2 (IL-2), interleukin 6 (IL-6) and tumor necrosis factor alpha (TNF- $\alpha)$ have been reported in patients with AS. ${ }^{4}$ Additionally, significant elevation in the level of $\mathrm{C}$-reactive protein (CRP) is present in AS patients. ${ }^{4}$

Apical periodontitis (AP) is the inflammation of the apical periodontium. This usually occurs following a bacterial invasion of the root canal system..$^{5}$ Similarly to AS, increased levels of cytokines and inflammatory mediators have been observed in the case of AP. ${ }^{6}$ Additionally, Sirin et al. reported that the level of CRP increases with the severity of AP. ${ }^{7}$ Many similarities in the pathogenesis of both AS and AP might suggest a relationship between them. However, there have been no studies evaluating the possible association between AS and AP. Previous studies have shown that there is a link between AS and periodontal disease. ${ }^{8,9}$ It has been concluded that patients with AS have a significantly higher risk of periodontal diseases than those without AS. ${ }^{9}$ Since AP and periodontitis share similar destructive inflammatory reactions and microbiota, it is possible that there is an association between AP and AS. Therefore, the present study aimed to investigate the possible association between AP and AS. The null hypothesis was that there would be no difference between the AS and control groups in terms of the prevalence of AP.

\section{Material and methods}

Fifty patients diagnosed with AS, receiving treatment at the Rheumatology Clinic in Erzurum, Turkey, were included in the experimental group. None of the patients were suffering from any other systemic disease, and all the patients included in the experimental group were on anti-TNF- $\alpha$ therapy. Another 50 age- and gender-matched individuals without any history of systemic disease were included in the study as the control group. Ethical approval for the pair-matched crosssectional study was obtained from the Ethics Committee of Atatürk University in Erzurum, Turkey (decision No. 9 as of November 1, 2018) and written informed consent was obtained from all the participants. The study was conducted between January 2, 2018 and January 12, 2018.

Patients with a complete medical and dental history, including panoramic radiographs of the maxilla and mandible, in the age range of 18-65 years, were included. Patients with fewer than 10 teeth present were excluded.

Two examiners who were blinded to the groups evaluated the panoramic radiographs in order to diagnose teeth with AP (Fig. 1,2). Both researchers studied the radiographs simultaneously. If both agreed on the diagnosis of AP, their findings were further confirmed clinically using the pulp vitality, percussion and palpation tests. The following information was recorded for all participants: the smoking habit, the number of teeth present, the number of teeth with AP, the number of root canaltreated (RCT) teeth, and the number of RCT teeth with AP. There were no differences between the researchers in terms of diagnosing AP radiographically.

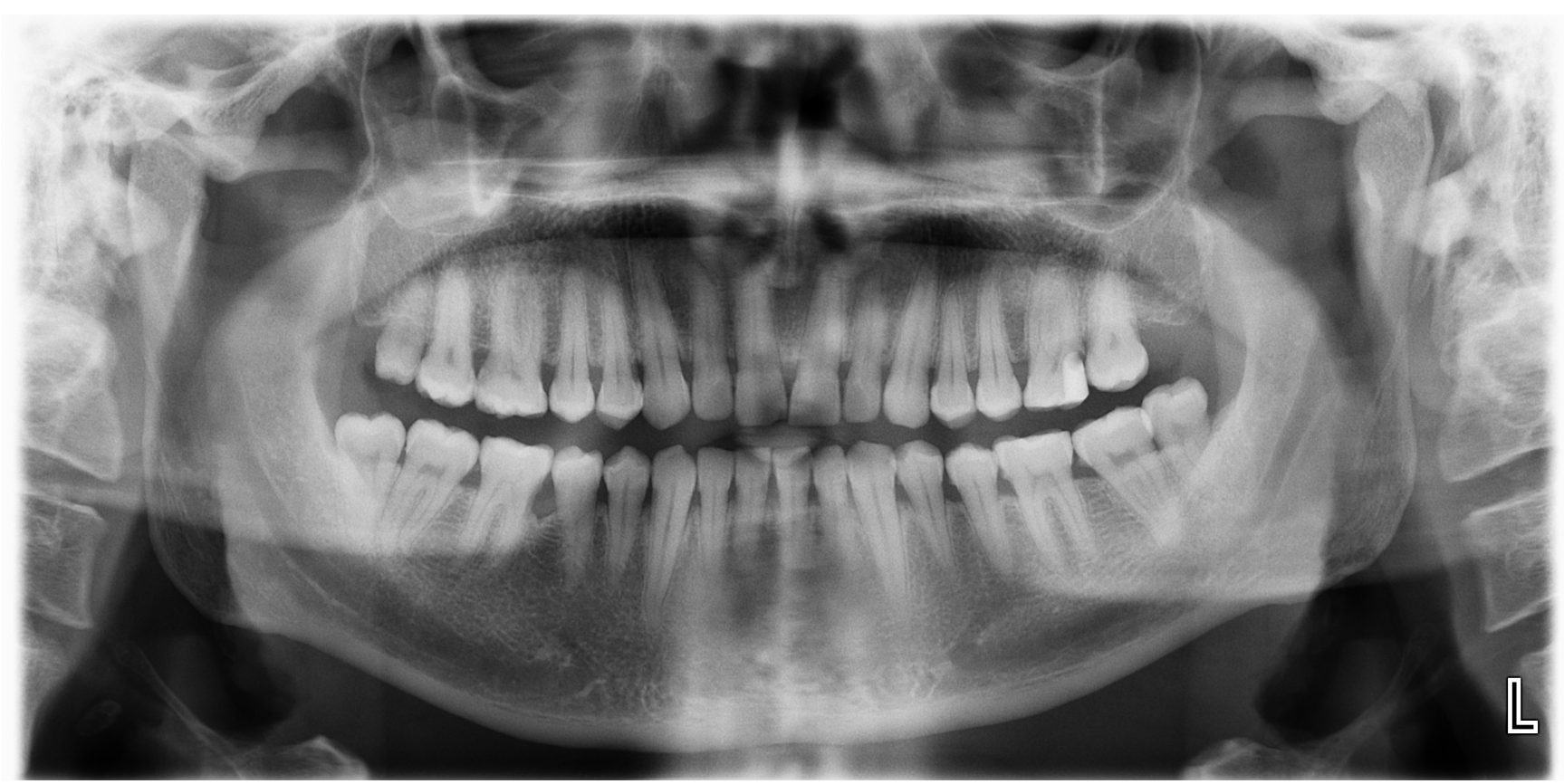

Fig. 1. Panoramic radiograph of a patient included in the control group 


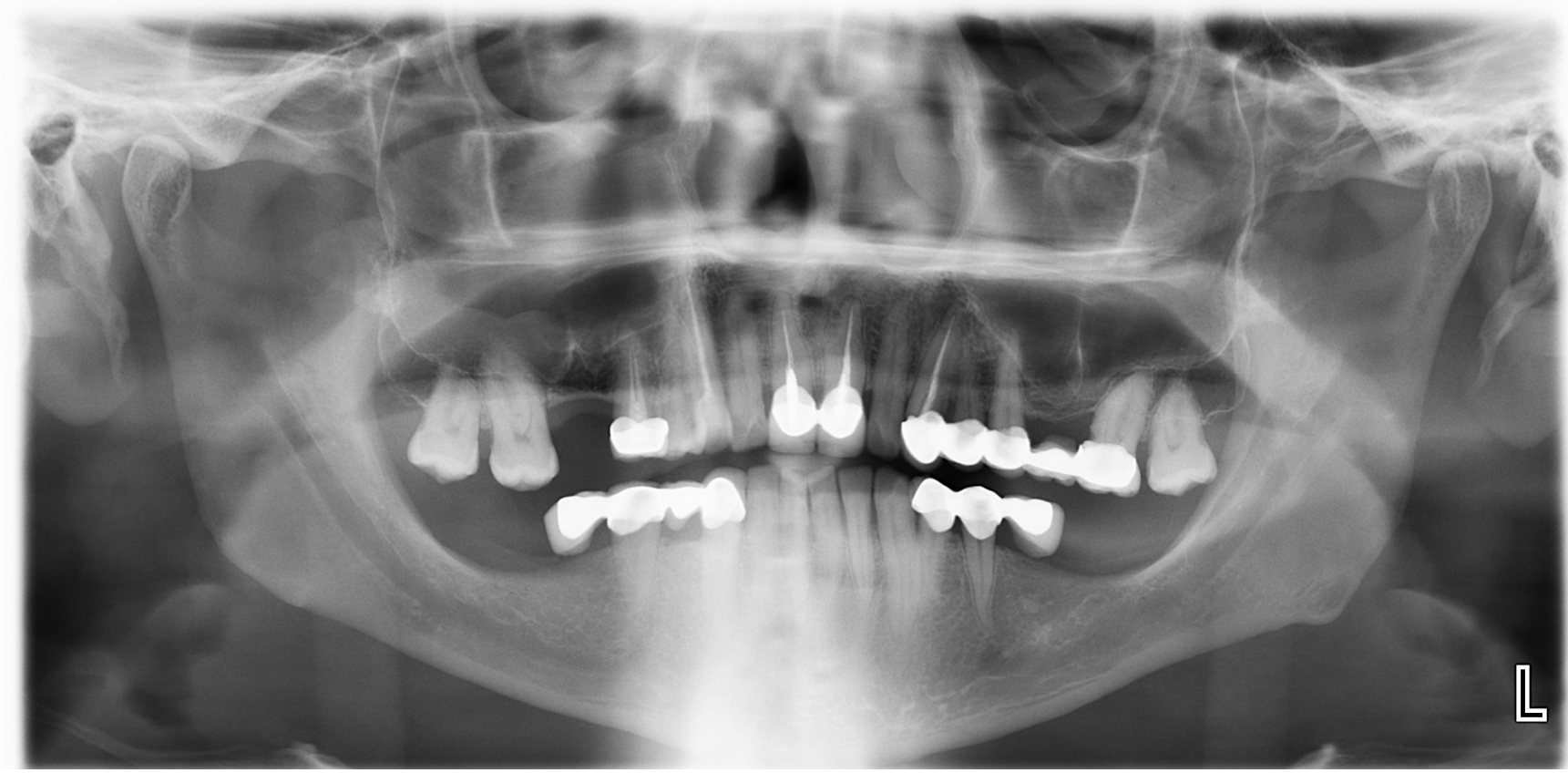

Fig. 2. Panoramic radiograph of a patient included in the experimental group

Due to the cross-sectional nature of the study, patients who had undergone primary root canal treatment were included. Therefore, the cause of endodontic treatment and the time elapsed since the completion of the treatment could not be recorded.

The inflammatory size measurement was performed using the periapical index (PAI). Teeth with normal periapical structure or with small changes in bone structure were categorized as healthy (PAI 1 and PAI 2). Teeth with a widened periodontal ligament, periodontitis with a well-defined radiolucent area and/or severe periodontitis with exacerbating features were categorized as teeth with periapical pathology (PAI3, PAI 4 andPAI 5). ${ }^{10}$ The periapical status of multi-rooted teeth was determined by the highest PAI score of all roots. ${ }^{11}$

The sample size was based on the data of the study's evaluated association between periapical rarefying osteitis and $\mathrm{AP},{ }^{12}$ with an effect size of 0.1 , an error of alpha equal to 0.05 and a power of 0.8. The IBM SPSS Statistics for Windows, v. 20 software (IBM Corp., Armonk, USA) was used for the statistical analyses at a significance level of $5 \%(p=0.05)$. The $\chi^{2}$ test was used to determine the possible association between AS and AP. Student's $t$-test was used to compare the age variable between the groups.

\section{Results}

A total of 100 participants with 2,588 teeth were examined. There were 1,283 teeth in the AS group and 1,305 in the control group. The number of teeth with AP in the AS group was 37 (2.9\%), whereas in the control group it was 17 (1.3\%). There was a significant association between teeth with AP and AS, as the prevalence of teeth with AP was significantly lower in the control group (1.3\%) than in the AS group $(2.9 \%)(O R$ (odds ratio) $=2.250 ; p=0.005)$ (Table 1$)$.

There were 34 (2.7\%) and 38 (2.9\%) RCT teeth in the AS and control groups, respectively. There was no statistically significant difference between the groups in terms of the number of RCT teeth $(O R=0.908 ; p=0.686)$. In the AS group, the number of RCT teeth with AP was 13 (1.0\%), whereas in the control group, the number of RCT teeth with AP was 7 (0.5\%). The difference between the groups was not statistically significant $(O R=1.898 ; p=0.166)$.

Table 1. Distribution of the analyzed variables in the patients with ankylosing spondylitis (AS) and in the control group

\begin{tabular}{|c|c|c|c|c|}
\hline Variable & $\begin{array}{c}\text { AS } \\
\text { (50 patients, } \\
1,283 \text { teeth) }\end{array}$ & $\begin{array}{c}\text { Control } \\
\text { (50 patients, } \\
1,305 \text { teeth) }\end{array}$ & $p$-value & OR \\
\hline Age & $37.98 \pm 9.06$ & $37.60 \pm 9.70$ & 0.840 & - \\
\hline $\begin{array}{l}\text { Gender } \\
\text { female } \\
\text { male }\end{array}$ & $\begin{array}{l}13 \\
37\end{array}$ & $\begin{array}{l}13 \\
37\end{array}$ & - & - \\
\hline $\begin{array}{l}\text { Smoking habit } \\
\text { present } \\
\text { absent }\end{array}$ & $\begin{array}{l}22(44.0) \\
28(56.0)\end{array}$ & $\begin{array}{l}22(44.0) \\
28(56.0)\end{array}$ & 1.000 & 1.000 \\
\hline $\begin{array}{l}\text { Teeth with AP } \\
\text { present } \\
\text { absent }\end{array}$ & $\begin{array}{c}37(2.9) \\
1,246(97.1)\end{array}$ & $\begin{array}{c}17(1.3) \\
1,288(98.7)\end{array}$ & $0.005^{*}$ & $2.250^{*}$ \\
\hline $\begin{array}{l}\text { RCT teeth } \\
\text { present } \\
\text { absent }\end{array}$ & $\begin{array}{c}34(2.7) \\
1,249(97.3)\end{array}$ & $\begin{array}{c}38(2.9) \\
1,267(97.1)\end{array}$ & 0.686 & 0.908 \\
\hline $\begin{array}{l}\text { RCT teeth with AP } \\
\text { present } \\
\text { absent }\end{array}$ & $\begin{array}{c}13(1.0) \\
1,270(99.0)\end{array}$ & $\begin{array}{c}7(0.5) \\
1,298(99.5)\end{array}$ & 0.166 & 1.898 \\
\hline
\end{tabular}

Data presented as mean \pm standard deviation $(M \pm S D)$, number $(n)$ or number (percentage) ( $n(\%))$.

$O R$ - odds ratio; AP - apical periodontitis; RCT - root canal-treated;

* statistically significant. 
There was no significant difference between the groups regarding the smoking habit $(p=1.000)$. The mean age of patients in the AS and control groups was $37.98 \pm 9.06$ and $37.60 \pm 9.70$ years, respectively $(p=0.840)$.

\section{Discussion}

Apical periodontitis is associated with increased levels of cytokines and inflammatory mediators, such as immunoglobulin A (IgA), immunoglobulin G (IgG), immunoglobulin M (IgM), interleukin 1 (IL-1), IL-2, IL-6, and CRP. ${ }^{6}$ Interleukin 2 and IL- 6 are normally secreted by T cells, and IL-2 plays an important role in immune regulation. ${ }^{13}$ Interleukin 6 may act both as an anti-inflammatory cytokine by activing in muscles, and as a pro-inflammatory cytokine by signaling in macrophages or monocytes. ${ }^{14}$ Elevated levels of TNF- $\alpha$ have also been observed in the process of AP development, which is related to the development of periapical granuloma and radicular cysts. ${ }^{15}$ As mentioned previously, elevated levels of IL-2, IL-6, TNF- $\alpha$, and CRP have also been reported in patients with $\mathrm{AS} .{ }^{4}$ It has been asserted that IL-2 can interfere with various signs and symptoms of AS, ${ }^{16}$ and TNF- $\alpha$ and IL- 6 could possibly reflect the parameters of disease activity in patients with AS. ${ }^{4}$ All these similarities in the pathogenesis of AP and AS could explain the higher prevalence of AP in the patients with AS.

According to the results of the present study, there was no statistically significant difference between the groups in terms of RCT teeth with AP. It can be suggested that the presence of AS does not restrict the healing response of patients with regard to root canal treatment, and does not reduce the success rate of endodontic treatment. In the present study, patients on anti-TNF- $\alpha$ therapy were included in the experimental group. It has been reported that patients undergoing such therapy are associated with faster healing of AP as compared to the control group. ${ }^{17}$ The increased level of TNF- $\alpha$ in the AS patients would have been reduced by anti-TNF- $\alpha$ therapy, and this might have resulted in unchanged healing outcomes, similar to those of the control group patients. However, we must take into account several immunologic factors that are related to the process of AS. Additionally, the mean time elapsed since the completion of root canal treatment was unknown. This is a limitation of the cross-sectional design. Moreover, due to the cross-sectional nature of the research, it is impossible to establish a true cause-andeffect relationship.

Previous studies have evaluated the association between AP and such systemic diseases as diabetes mellitus, ${ }^{11}$ endstage renal disease $\mathrm{e}^{18}$ and coronary artery disease. ${ }^{19}$ These studies analyzed the number of patients with at least 1 AP lesion, but the total number of teeth with AP was not taken into account. However, in the present study, the total number of teeth with AP was considered. In this way, a larger sample size was analyzed in order to evaluate the prevalence of AP in the patients with AS. Additionally, in the present study, the presence of AP was confirmed with a radiographic evaluation and a clinical examination.

\section{Conclusions}

Within the limitations of the present study, AS is significantly associated with an increased prevalence of AP. It can be concluded that patients with AS may be more prone to developing AP. However, AS does not reduce the success rate of endodontic treatment, as there was no significant difference between the AS and control groups in terms of RCT teeth with AP. Further studies involving the prospective design are needed to confirm the relationship between AS and AP.

\section{ORCID iDs}

Ertuğrul Karataş (1) https://orcid.org/0000-0002-8145-8763

Ayhan Kul (1) https://orcid.org/0000-0003-1313-9469

Ebru Tepecik (1) https://orcid.org/0000-0002-2964-3726

\section{References}

1. Braun J, Bollow M, Remlinger G, et al. Prevalence of spondylarthropathies in HLA-B27 positive and negative blood donors. Arthritis Rheum. 1998;41(1):58-67.

2. Reveille JD, Weisman MH. The epidemiology of back pain, axial spondyloarthritis and HLA-B27 in the United States. Am J Med Sci. 2013;345(6):431-436.

3. Braun J, Sieper J. Ankylosing spondylitis. Lancet. 2007;369(9570):1379 -1390 .

4. Bal A, Unlu E, Bahar G, Aydog E, Eksioglu E, Yorgancioglu R. Comparison of serum IL-1 beta, sIL-2R, IL-6, and TNF-alpha levels with disease activity parameters in ankylosing spondylitis. Clin Rheumatol. 2007;26(2):211-215.

5. Márton IJ, Kiss C. Overlapping protective and destructive regulatory pathways in apical periodontitis. J Endod. 2014;40(2):155-163.

6. Gomes MS, Blattner TC, Sant'Ana Filho M, et al. Can apical periodontitis modify systemic levels of inflammatory markers? A systematic review and meta-analysis. J Endod. 2013;39(10):1205-1217.

7. Sirin DA, Ozcelik F, Uzun C, Ersahan S, Yesilbas S. Association between C-reactive protein, neutrophil to lymphocyte ratio and the burden of apical periodontitis: A case-control study. Acta Odontol Scand. 2019;77(2):142-149.

8. Keller JJ, Kang JH, Lin HC. Association between ankylosing spondylitis and chronic periodontitis: A population-based study. Arthritis Rheum. 2013;65(1):167-173.

9. Pischon N, Pischon T, Gülmez E, et al. Periodontal disease in patients with ankylosing spondylitis. Ann Rheum Dis. 2010;69(1):34-38.

10. Orstavik D, Kerekes K, Eriksen HM. The periapical index: A scoring system for radiographic assessment of apical periodontitis. Endod Dent Traumatol. 1986;2(1):20-34.

11. López-López J, Jané-Salas E, Estrugo-Devesa A, Velasco-Ortega E, Martín-González J, Segura-Egea JJ. Periapical and endodontic status of type 2 diabetic patients in Catalonia, Spain: A cross-sectional study. J Endod. 2011;37(5):598-601.

12. Jalali P, Glickman GN, Schneiderman ED, Schweitzer JL. Prevalence of periapical rarefying osteitis in patients with rheumatoid arthritis. J Endod. 2017;43(7):1093-1096.

13. Cantrell DA, Smith KA. The interleukin-2 T-cell system: A new cell growth model. Science. 1984;224(4655):1312-1316.

14. Brandt C, Pedersen BK. The role of exercise-induced myokines in muscle homeostasis and the defense against chronic diseases. J Biomed Biotechnol. 2010;2010:520258. 
15. Santos SCLT, Couto LA, Fonseca JM, et al. Participation of osteoclastogenic factors in immunopathogenesis of human chronic periapical lesions. J Oral Pathol Med. 2017;46(9):846-852.

16. Liu HC, Hsieh KH. Elevated serum interleukin-2 receptor; increased in vitro immunoglobulin synthesis and lack of response to testosterone-enhanced in vitro interleukin-2 production in ankylosing spondylitis. Zhonghua Min Guo Wei Sheng Wu Ji Mian Yi Xue Za Zhi. 1987;20(1):1-8.

17. Cotti E, Mezzena S, Schirru E, et al. Healing of apical periodontitis in patients with inflammatory bowel diseases and under anti-tumor necrosis factor alpha therapy. J Endod. 2018;44(12):1777-1782.

18. Khalighinejad N, Aminoshariae A, Kulild JC, Sahly K, Mickel A. Association of end-stage renal disease with radiographically and clinically diagnosed apical periodontitis: A hospital-based study. J Endod. 2017;43(9):1438-1441.

19. Costa $\mathrm{TH}$, de Figueiredo Neto JA, de Oliveira AE, Lopes e Maia Mde F, de Almeida AL. Association between chronic apical periodontitis and coronary artery disease. J Endod. 2014;40(2):164-167. 